\title{
Citation patterns in translation studies: a format-dependent bibliometric analysis
}

\author{
Sara Rovira-Esteva \\ Universitat Autònoma de Barcelona, Spain \\ Sara.rovira@uab.cat
}

\author{
Javier Franco Aixelá \\ University of Alicante, Spain \\ Javier.Franco@ua.es
}

\section{Christian Olalla-Soler}

Universitat Autònoma de Barcelona, Spain

Christian.Olalla@uab.cat

DOI: 10.12807/ti.111201.2019.a09

\begin{abstract}
Citation distributions vary across the board among academic disciplines, which is the reason why field-oriented normalisation is necessary to compensate for this. In this vein, the aim of this study is three-fold. Firstly, to find out which document type is cited the most in translation studies (TS). Secondly, to determine the time distribution for citations and aging patterns in TS scientific literature. Thirdly, to define a disciplineweighted citation window or cited half-life, in order to establish the optimal citation window to be used in TS. Data enabling the present research will be retrieved from BITRA, which includes over 70,000 items covering the diversity of document types and languages used in TS research for all times and the citing information of over $10 \%$ of its entries. This database will thus allow us to carry out a study on citation and aging patterns in TS academic literature covering the 1960-2015 period. Both, global results, as well as a more detailed analysis focusing on different document types, will be provided. This bibliometric study aims to offer a discipline-focused approach in order to develop specific and realistic impact criteria for our discipline, while taking into account its actual research and communication practices.
\end{abstract}

Keywords: bibliometrics, citation patterns, document type, impact, normalisation, translation studies

\section{Introduction}

The number of citations accrued to a document is often used as an indicator of the quality of that work. This kind of assessment, merely based on quantitative indiscriminate measurements, is problematic since, in Moed's (2005, p. 221) words, "[c]itations measure many aspects of scholarly activity at the same time." Actually, "[t]he 'citedness' of a publication does not tell us anything about its quality per se", since factors such as the publication language or the popularity of the subject are determining factors in this respect. In this sense, citations only provide "information about the current interests of the citing author(s) or about the impact of a publication on the scientific community" (Grbić \& Pöllabauer, 2008, p. 104). As Sugimoto and Larivière (2018, p. 64) point out, " $[t]$ he simplistic rationale for this is that if one paper cites another, it demonstrates some form of interaction and engagement wherein the citing paper builds upon the cited paper". However, it should also be taken into account that the reasons behind citations are diverse, that factors that have nothing to do with quality (such as publication language, topic or approach) 
exert a notable influence on citability (cf. Franco Aixelá, 2013), and that Translations Studies (TS) are probably not immune to what is known in scientometrics as the "Matthew effect", in other words, the tendency to cite articles written by well-known authors rather than drawing attention to the work of lesser-known researchers even if the latter's work is similar or better in quality. Therefore, in this paper, we do not take citations as indicators of research quality, but rather as indicators of the outreach and visibility of a given document. Taken collectively, citations also provide valuable clues as to the most influential subjects and approaches within a given discipline.

The uncritical and mechanistic application of current quality assessment instruments to academic production leads to false snapshots showing distorted pictures far removed from reality. Furthermore, bibliometric approaches to research assessment used in the natural sciences yield unsatisfying results when applied to the humanities for various reasons, such as different publication practices and channels, regional orientation or diverse research habits and practices (Hellqvist, 2010, p. 310; see also Hammarfelt, 2016, and Huang \& Chang, 2008). However, the rating of research through citation counts also has its advantages, notably its convenience and the avoidance of any subjective peer-assessment. Since citation counting seems to be here to stay, it seems necessary to embrace the discussion and enrich it with objective, discipline-focused data leading to a fairer implementation.

Citation distributions are widely assumed to vary across the board among academic disciplines and normalisation (i.e., the adjustment of bibliometric estimations to the expected citation rate within the discipline) is necessary to compensate for this (Waltman \& van Eck, 2013; Wouters et al., 2015, p. v). Since technological development and paradigm shifts are not as short-term as in the experimental sciences, the time pressure when it comes to keeping up with current research is less pronounced. Therefore, "scholars in the Humanities use sources that cover a wide age span" (Hammarfelt, 2016, p. 120). This is why "[o]ne of the recurrent problems in evaluating the Humanities is the long time span needed for measuring the impact of research" (p. 126).

Some authors have already criticized the fact that "there are substantial differences in scientific practice between the several disciplines within the humanities" (van den Akker, 2016, p. 25). For example, Rovira-Esteva, Franco Aixelá \& Olalla-Soler (2020) have found that TS scholars reveal distinctive scholarly behaviour and communication patterns in terms of authorship practices compared to their peers in linguistics. However, there is a lack of information about publication and dissemination practices in the Humanities, in general, and in TS in particular, and unfortunately, they are usually taken as a homogeneous whole in bibliometric research. Therefore, we deem it necessary to investigate the specificities of our discipline as far as citation patterns are concerned in order to take them into account when evaluating TS research or comparing its research performance with sister disciplines.

A number of TS scholars have already carried out studies in relation to citation analysis. Gile (2000) studied the popularity of single personalities in the history of conference interpreting research as reflected by citations. In a later publication, Gile (2005) focused on citation patterns in a corpus of didactics in translation and interpreting. Other authors have also contributed with empirical data combining publication counts with other kinds of analyses (Grbić, 2007; Grbić \& Pöllabauer, 2008; Metzger, 2006; Pöchhacker, 1995; Pöllabauer, 2006). However, most of the preceding studies were limited in scope, either because they focused on interpreting research or because the databases used for data analysis were relatively small. Moreover, none adopted a bibliometric approach proper i.e., none of them systematically used generally accepted statistical methods for their analysis of bibliographic data. 
Other studies that might complement the present one focus on citation rates in relation to publication language, (Franco Aixelá, 2010a, 2013; Franco Aixelá \& Rovira-Esteva, 2015, 2018), topic, (Franco Aixelá, 2010a, 2010b; Franco Aixelá \& Rovira-Esteva, 2015) or research approach (Franco Aixelá \& Rovira-Esteva, 2015). At present, our knowledge about publication and dissemination habits in TS is basically impressionistic, derived from personal observation or experience, but we still lack any systematic quantitative and qualitative data.

Given that research assessments are unavoidable and even desirable if adequately performed, scholars should take an active role in shaping the evaluation procedures that are used to assess TS research in order to prevent any negative consequences and to get as much benefit out of the exercise as possible. In other words, instead of developing individual defense mechanisms against research assessment in general, TS scholars should take command ourselves in developing adequate forms of research assessment. Since a crucial decision when making publication or citation counts is to select the time span of interest, and it has been recognised that citation distributions vary among the different fields of science, this crucial factor needs to be normalised. Bibliometric studies, such as the present one, can shed some light on the particularities of TS publication and communication culture, so that if their impact, or even quality, are evaluated through citation analysis, they are at least appropriately evaluated.

The objective of this study is, thus, three-fold. Firstly, to find out which document type is cited the most in TS. Secondly, to determine the time distribution of citations and the aging or obsolescence patterns of TS scientific literature. Thirdly, to define a discipline-weighted citation window or cited half-life, in order to establish the optimal citation window to be used in TS. In order to carry out these objectives, we will try to address the following research questions:

1) Which document type is most highly cited in TS on average? And has there been an evolution of this over time?

2) How long does it take, on average, for a TS publication to receive its first citation for each document type? And has there been an evolution of this over time?

3) What percentage of citations can be accrued by a TS publication in 2-year, 5-year, 10-year and 15-year time windows contingent on document type?

4) What is the cited half-life for a TS publication in relation to document type? And has there been an evolution in this aspect over time?

With all these results, we will be able, on the one hand, to give an overview of referencing practices and citation aging patterns, not only in accordance with document type, but also over time. While, on the other hand, we will have the means to determine TS field-weighted citation impact in order to find out how an individual scholar's outputs should be assessed in terms of the number of citations received as compared with the average in similar publications, with regard to format, in our particular field.

\section{Data and methods}

\subsection{Bibliography of Interpreting and Translation}

The largest commercial (mainly experimental/science-oriented) citation databases such as Web of Science (WoS) or Scopus present an inadequate coverage of TS publications. In 2017 only $8.5 \%$ and $27 \%$ of TS current 
journals were indexed in the Journal Citation Reports (JCR) and Scimago Journal \& Country Rank (SJR), respectively. ${ }^{1}$ Therefore, these databases are not representative of research carried out in our field (and even less so if we need to take into account all the publicaton formats, and not just journal articles). Consequently, they are insufficient for evaluation. Grbić \& Pöllabauer (2008, p. 94) criticised the lack of large-scale databases and the fact that none of the databases in TS which were available at that time included inter-document citation information. Since then, BITRA (Bibliography of Interpreting and Translation) (see Franco Aixelá, 2001-2018) has tried to address this issue by including citations in its entries. The data used in this present research has been retrieved from BITRA for the following five reasons.

Firstly, this database is the most comprehensive international database with bibliographic data for scholarly TS publications, including over 70,000 items and covering a diversity of document types and languages used in TS research throughout history. It is virtually impossible to know the exact size and composition of our population of study, but the number of entries currently included in BITRA is by no means negligible and we believe it currently covers most visible TS production, at least as far as work produced in the West is concerned. ${ }^{2}$

Secondly, TS research that is not published in journals indexed in the WoS remains largely invisible to conventional bibliometrics. Therefore, from the point of view of methodology, using a bibliographical database that includes all types of TS documents, as well as publications not written in English that are seldom covered by traditional bibliometric approaches, represents a major advantage for bibliometric research in our field.

Thirdly, Huang and Chang (2008, p. 1826) affirm that evaluations based on citation analyses in the social sciences and humanities require longitudinal data to better reflect the long-term use in their literatures. BITRA allows us to carry out a large-scale study on citation and the aging patterns of TS academic literature covering a lengthy time span (1960-2015).

Fourthly, BITRA has already collected citation data from over $10 \%$ of its entries. This relatively new feature, with some 100,000 citations already assigned to the corresponding cited documents, is a good solution for overcoming the limits of existing data sources and opens up new research perspectives. $^{3}$

Last but not least, there is a consensus in the literature that citation counts of publications from different fields should not be directly compared with each other. Consequently, we need to normalize citation impact indicators, and a key issue in the calculation of these normalised citation impact indicators is the way in which the concept of a scientific field is operationalised. One of the possible ways this can be undertaken is through predefined database fields (Wouters et al., 2015, p. v). BITRA is a comprehensive database containing structured information on the various types of output in TS. Since more references are expected in some fields than in others, using a TS-specific database solves the problem of the delineation of an appropriate set of publications for use as a comparison or reference set. We are thus carrying out a form of source-normalisation i.e., we choose to eliminate the underlying discipline-related difference in the citation behavior

\footnotetext{
${ }^{1}$ Data retrieved from RETI (see Biblioteca d'Humanitats. Universitat Autònoma de Barcelona, 2018).

${ }^{2}$ The clearest evidence for this can be obtained by checking how many TS references from any TS journal issue are already covered by this database. Systematically, the answer to this question is over $70 \%$.

${ }_{3}$ The main criteria in the mining of documents for their citations in BITRA are diversity, visibility and topicality. For further details, please see: https://dti.ua.es/en/bitra/impact.html.
} 
of the citing authors. For further information about the normalisation of our data, please refer to Subsection 2.1.2.

\subsubsection{From BITRA to a comprehensive ad hoc database for the analysis of citation patterns in translation studies}

To perform our analysis, all documents included in BITRA that had been cited at least once and those that had cited any other document were exported and converted into a new database. In order to work with a homogeneous sample, a period of analysis ranging from 1960 to 2015 was established. Documents published before 1960 and after 2015 were deleted from the database. The main reasons for choosing 1960 and 2015 as endpoints are, on the one hand, that there are very few citations to the fewer than 2000 documents dating before 1960 and, on the other, that after 2015 only a small percentage of the citations can be detected as yet. Once the database was built, it was checked in order to find and correct any errors. In April 2017, BITRA initially contained 69,056 documents (many of them previous to our period of study or without citations). All document types except $\mathrm{PhD}$ theses were selected, namely books, book chapters, journal articles and journal special issues, ${ }^{4}$ obtaining a total of 66,407 documents. However, among these only 25,303 (38.1\%) had at least one citation detected in our database. After the process of sifting and discarding non-cited and non-citing documents, our database contained 27,961 items: 21,375 cited documents with at least one citation, 3928 citing documents with at least one citation, and 2658 citing documents without citations. This means that 38,446 publications with no detected citations or whose citations were as yet unmined (representing $57.9 \%$ of the total) were excluded from our study. The percentage of non-cited documents is noteworthy and obviously relevant for analysis. However, this will not be included in the calculations carried out in this paper because here we are focussing on citation patterns.

In our database, the following two variables were analysed: publication year and publication type. Each row in the database corresponds to one citation to a cited document. Data was grouped into ten-year periods - except for the last one - in order to facilitate analysis. Table 1 summarizes the number of published documents and number of citations accrued by period and publication type.

\footnotetext{
${ }^{4}$ We have tried to use broadly accepted labels for the different formats. Thus, journal article stands for any academic articles (book reviews exclusive) published in journals. The book category includes both collective volumes and monographs since that is the usual bibliographical procedure and also the classification method in BITRA, although in the future it would be interesting to compare the citability of edited and authored volumes. Book chapter refers to chapters in edited volumes. The term journal special issue refers to thematic issues in which all the articles deal with the same topic and which are usually coordinated by guest editors who are experts in a chosen field. They were included because we considered results could be especially interesting for journal editors. In this case, we are referring to citations to special issues as such, not to citations of papers in special issues. PhD theses were excluded because they could bias the results. On the one hand, since they are a special document type difficult to detect and we feared that at the time of conducting this research they would probably not be well represented in BITRA. On the other hand, they tend to have long reference lists, a reason why they are not systematically mined.
} 
Table 1. Number of documents and citations by period and publication type

\begin{tabular}{|c|c|c|c|c|c|c|c|c|}
\hline & & $\begin{array}{l}1960- \\
1969\end{array}$ & $\begin{array}{c}1970- \\
1979 \\
\end{array}$ & $\begin{array}{c}1980- \\
1989\end{array}$ & $\begin{array}{l}1990- \\
1999\end{array}$ & $\begin{array}{l}2000- \\
2009\end{array}$ & $\begin{array}{l}2010- \\
2015 \\
\end{array}$ & Total \\
\hline \multirow{2}{*}{$\begin{array}{l}\text { Journal } \\
\text { article }\end{array}$} & Items & 332 & 479 & 1151 & 2885 & 5173 & 3003 & 13,023 \\
\hline & Citations & 80 & 169 & 243 & 2651 & 10,711 & 11,488 & 25,342 \\
\hline \multirow{2}{*}{ Book } & Items & 140 & 275 & 572 & 1186 & 1692 & 590 & 4455 \\
\hline & Citations & 38 & 200 & 390 & 4484 & 17,353 & 12,590 & 35,055 \\
\hline \multirow{2}{*}{$\begin{array}{l}\text { Book } \\
\text { chapter }\end{array}$} & Items & 129 & 299 & 1005 & 2919 & 4619 & 1262 & 10,233 \\
\hline & Citations & 45 & 102 & 279 & 2497 & 11,271 & 9538 & 23,732 \\
\hline \multirow{2}{*}{$\begin{array}{l}\text { Journal } \\
\text { special } \\
\text { issue }\end{array}$} & Items & 2 & 8 & 24 & 56 & 100 & 60 & 250 \\
\hline & Citations & 0 & 0 & 2 & 92 & 384 & 346 & 824 \\
\hline
\end{tabular}

\subsubsection{Data preparation and normalisation}

As can be seen in Table 1, each publication type presents differences in the density of documents published and number of citations detected in each period. This could affect the analysis of the citation patterns. As De Bellis (2009, p. 116) observes, "[a] corrective factor is required if citation rates are to be adjusted for changes in the size for the citing population (...)". To achieve one of the aims we established, we needed to calculate the time span between the publication year of the cited document and the publication year of the citing document. Thus, we needed to normalize the waiting time, in years, for each publication type in order to correct any possible bias in our analysis. To do this, we used Moed, Van Leeuwen, and Reedijk's correction (1999) for each publication type. We could then calculate the corrected cited half-life, which is the main bibliometric indicator that we have used in our analysis.

Publications tend to concentrate citations during the first years after the work is published and citations decrease over time, which is a typical distribution for this kind of data (Bouabid, 2011). This is also the case in TS, as shown in Figure 1, where the distribution of the difference between the publication year of the citing documents and the publication year of the cited documents is right-skewed.

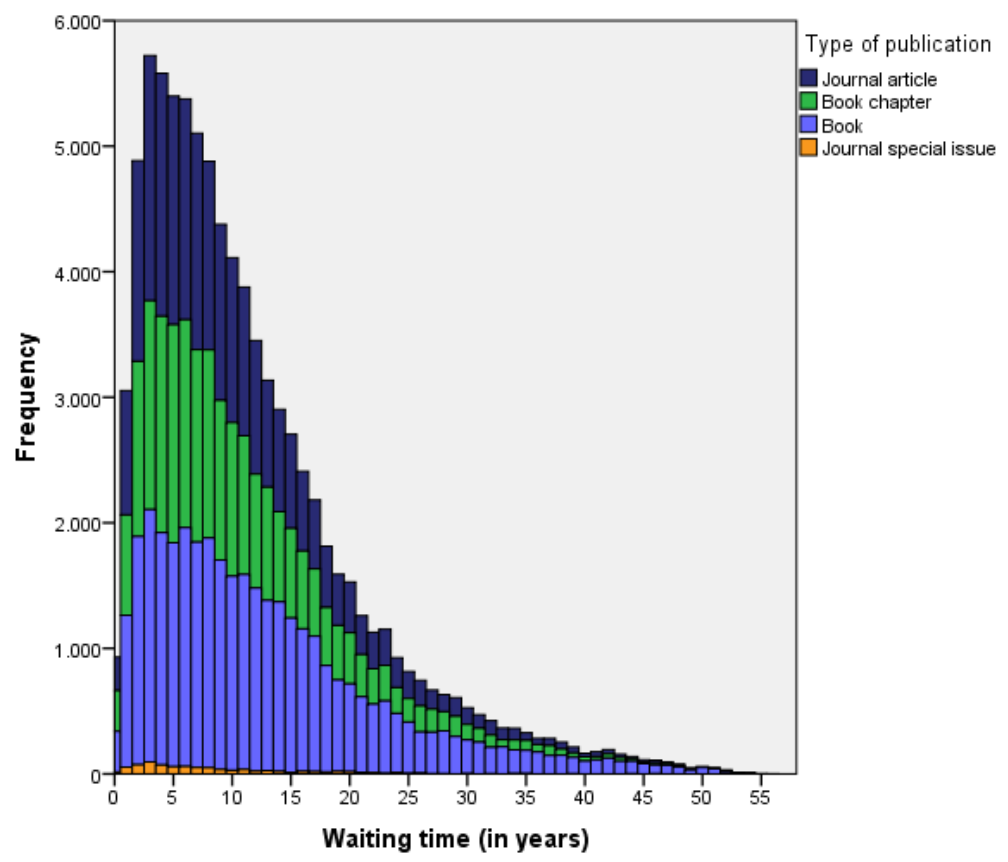

Figure 1. Distribution of the difference between the citing documents' publication year and that of the cited documents 
All publication types are highly skewed (journal article $=1.5$, book chapter $=1.4$; book $=1.2$, and journal special issue $=1.3$ ). We identified the outliers of each publication type and determined their impact on the analysis. Since their impact was high (that is, central-tendency values were highly distorted when they were included), we decided to trim them off by setting a cut-off value of three standard deviations.

\subsection{Methods}

In this section, we will present the calculation methods we have used to obtain the results in answer to our research questions. Since the distribution is skewed, the mean is too sensitive to extreme values. This is the reason why the median (Mdn), as a more robust measure to better describe the centre of our data, is the main value used as a reference for our analysis. The median absolute deviation (MAD) was calculated as a measure of dispersion, since it is also a statistic that is more robust when faced with extreme values than is the standard deviation. Nonetheless, when presenting the results of the number of citations sorted by document type, we found that it was highly informative to also report the mean in order to account for the high sensitivity of this central tendency statistic to extreme values. The only case in which we used and interpreted the mean as a statistic for the central tendency was when computing the percentage of citations accrued within each time window.

In order to answer the first research question and to find out which document type is likely to accrue more citations in TS, we calculated the mean, the median and the median absolute deviation both for the whole period under study (1960-2015) and in ten-year blocks to facilitate data analysis.

For the second research question, namely, "how long does it take on average for a TS publication to receive its first citation for each document type?", only the first citation of each cited document was selected. As already mentioned, the corrected median and mode for each publication type for the whole period of analysis (1960-2015) was calculated following Moed, Van Leeuwen, and Reedijk's method (1999). The median indicates the median age of the documents that were cited for the first time in the period under analysis (1960-2015). We also calculated the median absolute deviation for each publication type. The mode describes the waiting time, in years, in which most of the cited documents receive their first citation. Both the median of years needed to receive the first citation and the mode provide useful and complementary information to describe and interpret first-citation patterns by publication types. For a deeper analysis, we created life tables and plotted the cumulative distribution of the survival function by publication type. In this article, only the plot is presented for reasons of space. The cumulative distribution of the survival function provides the probability that a document be cited for the first time beyond any given specified time. For this calculation, citing documents for which no citation was detected during the whole period of analysis were used as censored cases i.e., cases in which the condition of being cited has not been accomplished within the specified time period.

The corrected median was calculated by publication type and decades (1960-1969, 1970-1979, 1980-1989, 1990-1999, 2000-2009, and the 6-year period 2010-2015). Our results show the evolution of the median of years needed to receive a first citation in the abovementioned periods. Finally, we calculated the mode for each period and publication type.

As for the third research question i.e., "what percentage of citations can be accrued by a TS publication in 2-year, 5-year, 10-year and 15-year time windows contingent on document type?", we first established the abovementioned citation windows. We then calculated the percentage of citations for each document accrued during each citation window in relation to all of the citations accrued by each publication during the whole period of 
analysis (1960-2015). After performing this calculation, we computed the mean for each publication type and each citation window. The results show the percentage of citations that are covered in each citation window for each publication type.

To answer the fourth research question, namely, "what is the cited halflife for a TS publication in relation to document type?", we calculated the cited half-life for all citations of each cited document. The cited half-life indicates the median age of the documents that were cited in the period of analysis (1960-2015). We also calculated the citation peak, which indicates the waiting time, in years, in which most of the cited documents received the most citations.

Due to the nature of the data we are dealing with, the normality assumption could not be met. ${ }^{5}$ Transforming our data to meet this assumption could distort the interpretation of the results. Thus, all comparisons between publication types were carried out with the Kruskal-Wallis test as an omnibus test and the Mann-Whitney $U$ test for the post-hoc tests using the Bonferroni correction. Effect sizes are provided for all tests. We set the alpha level at 5\%.

\section{Results}

3.1. Number of citations to TS research outputs in relation to document type Despite the fact that, according to our data, journal articles are the most frequent document type (see Table 1), globally, books accrue more citations. The results for the first research question, namely, which document type is most highly cited in TS for the whole period under study (1960-2015) are shown in tables 2 and 3 .

Table 2. Mean, median, and median absolute deviation of citations per document by publication type for the whole period (1960-2015)

\begin{tabular}{|l|r|r|c|}
\hline \multicolumn{4}{|c|}{ Descriptive statistics (normalised values) } \\
\hline Type of document & Mean & Median & $\begin{array}{c}\text { Median absolute } \\
\text { deviation }\end{array}$ \\
\hline Journal article & 2.6 & 1.0 & 1.6 \\
\hline Book & 8.1 & 2.0 & 7.0 \\
\hline Book chapter & 2.7 & 1.0 & 1.7 \\
\hline Journal special issue & 3.4 & 1.0 & 2.4 \\
\hline
\end{tabular}

While journal articles, book chapters and journal special issues receive approximately the same mean of citations per document, books are the publication type that concentrates more citations per document; more than double that of other document types. A Kruskal-Wallis test confirmed that there are small differences in the number of citations received by each publication type $\left(H[3]=599.1 ; p<0.001 ; \eta^{2}=0.03\right)$. Post-hoc tests showed that differences were observable between books and journal articles $(U=$ 2646.4; $p<0.001 ; r=0.23)$, books and book chapters $(U=-2431.4 ; p<$ $0.001 ; r=0.21)$, and books and journal special issues $(U=1940.7 ; p<0.001$; $r=0.16)$. However, journal articles, book chapters and journal special issues did not differ significantly among themselves. The difference between the mean and median values is remarkable. As mentioned earlier, the mean is more sensitive to the extreme values contained in the dataset than is the median. While the median values reported do not differ greatly among

\footnotetext{
${ }^{5}$ Non-normal distribution is the norm in bibliometric studies, where productivity and impact are "markedly skewed, conforming to a hyperbolic pattern" (De Bellis, 2009, p. 77, p. 84-88, p. 209).
} 
themselves, the absolute median deviation clearly reflects the differences between publication types.

As Hammarfelt (2016, p. 127) already noted, research on scholarly communication is also needed in order to track changes in research practices due "to technical developments (digitalization), external demands (research evaluation, open access) and internal negotiations on the purpose of research". We thus carried out a diachronic analysis to find out if publication practices as far as cited documents are concerned have evolved within TS (see Table 3 for results).

Table 3. Mean (m) and median (Mdn) of citations per document according to publication type and period

\begin{tabular}{|c|c|c|c|c|c|c|}
\hline & $1960-1969$ & 1970-1979 & $1980-1989$ & $1990-1999$ & $2000-2009$ & 2010-2015 \\
\hline $\begin{array}{l}\text { Journal } \\
\text { article }\end{array}$ & $\begin{array}{r}m=1.8 \\
M d n=1 \\
(n=332)\end{array}$ & $\begin{array}{r}m=2.8 \\
M d n=1 \\
(n=475)\end{array}$ & $\begin{array}{r}m=3.0 \\
M d n=1 \\
(n=1142)\end{array}$ & $\begin{array}{r}m=3.1 \\
M d n=1 \\
(n=2747)\end{array}$ & $\begin{array}{r}m=2.5 \\
M d n=1 \\
(n=4135)\end{array}$ & $\begin{array}{r}m=1.7 \\
M d n=1 \\
(n=1283)\end{array}$ \\
\hline Book & $\begin{array}{l}m=13.8 \\
M d n=2 \\
(n=140)\end{array}$ & $\begin{array}{r}m=9.1 \\
M d n=2 \\
(n=275)\end{array}$ & $\begin{array}{r}m=9.7 \\
M d n=2 \\
(n=572)\end{array}$ & $\begin{array}{r}m=12.6 \\
M d n=2 \\
(n=1182)\end{array}$ & $\begin{array}{r}m=5.8 \\
M d n=2 \\
(n=1679)\end{array}$ & $\begin{array}{r}m=2.5 \\
M d n=1 \\
(n=589)\end{array}$ \\
\hline $\begin{array}{l}\text { Book } \\
\text { chapter }\end{array}$ & $\begin{array}{r}m=3.3 \\
M d n=1 \\
(n=129)\end{array}$ & $\begin{array}{r}m=4.8 \\
M d n=1 \\
(n=297)\end{array}$ & $\begin{array}{r}m=3.4 \\
M d n=1 \\
(n=1002) \\
\end{array}$ & $\begin{array}{r}m=3.0 \\
M d n=1 \\
(n=2861)\end{array}$ & $\begin{array}{r}m=2.3 \\
M d n=1 \\
(n=3906)\end{array}$ & $\begin{array}{r}m=1.6 \\
M d n=1 \\
(n=950)\end{array}$ \\
\hline $\begin{array}{l}\text { Journal } \\
\text { special } \\
\text { issue }\end{array}$ & $\begin{array}{r}m=2.0 \\
M d n=2 \\
(n=2)\end{array}$ & $\begin{array}{r}m=1.3 \\
M d n=1 \\
(n=8)\end{array}$ & $\begin{array}{l}m=3.0 \\
M d n=1 \\
(n=24)\end{array}$ & $\begin{array}{r}m=6.1 \\
M d n=2 \\
(n=56)\end{array}$ & $\begin{array}{r}m=1.3 \\
M d n=1 \\
(n=100)\end{array}$ & $\begin{array}{r}m=1.7 \\
M d n=1 \\
(n=60)\end{array}$ \\
\hline
\end{tabular}

The proportion of citations and documents published in each period increases from the sixties until the nineties and then starts decreasing for all document types. However, the decreasing trend in book chapters starts much earlier (1980-1989).

In order to find out if the differences shown in Table 3 were statistically significant, we compared different document types and periods. We left journal special issues out of the tests because this document type cannot be considered an individual research output and, therefore, it is not comparable to the rest as far as personal research assessments are concerned. Moreover, for reasons of space, we prioritised the last two periods because they present the most recent citation patterns (results are shown in Table 4).

Table 4. Omnibus tests and post-hoc tests by period and comparison tests by publication type

\begin{tabular}{|c|c|c|c|c|c|c|c|}
\hline \multicolumn{4}{|c|}{$\begin{array}{c}\text { Omnibus tests and post-hoc tests by } \\
\text { publication type }\end{array}$} & \multicolumn{4}{|c|}{ Comparison tests by publication type } \\
\hline \multicolumn{4}{|c|}{ 2000-2009: $H(2)=200.8, p<0.001, \eta^{2}=0.02$} & \multicolumn{4}{|c|}{$1990-1999$ vs. $2000-2009$} \\
\hline & $U$ & $p$ & $r$ & & $U$ & $p$ (one-tailed) & $r$ \\
\hline $\begin{array}{l}\text { Journal articles } \\
\text { vs. book } \\
\text { chapters }\end{array}$ & 39.6 & $=1.0$ & 0.01 & Articles & 5589099.5 & $=0.10$ & 0.02 \\
\hline $\begin{array}{l}\text { Journal articles } \\
\text { vs. books }\end{array}$ & -945.7 & $<0.001$ & 0.19 & Books & 891148.0 & $<0.001$ & 0.11 \\
\hline $\begin{array}{l}\text { Book chapters } \\
\text { vs. books }\end{array}$ & 985.3 & $<0.001$ & 0.20 & $\begin{array}{l}\text { Book } \\
\text { chapters }\end{array}$ & 5301471.0 & $<0.001$ & 0.05 \\
\hline \multicolumn{4}{|c|}{ 2010-2015: $H(2)=79.5, p<0.001, \eta^{2}=0.03$} & & & & \\
\hline & $U$ & $p$ & $r$ & & & & \\
\hline $\begin{array}{l}\text { Journal articles } \\
\text { vs. book } \\
\text { chapters }\end{array}$ & 10.0 & $=1.0$ & 0.01 & & & & \\
\hline $\begin{array}{l}\text { Journal articles } \\
\text { vs. books }\end{array}$ & -278.5 & $<0.001$ & 0.20 & & & & \\
\hline $\begin{array}{l}\text { Book chapters } \\
\text { vs. books }\end{array}$ & 288.5 & $<0.001$ & 0.21 & & & & \\
\hline
\end{tabular}


The differences between journal articles and book chapters for both the 2000-2009 and 2010-2015 periods are not statistically significant. Conversely, the differences between journal articles and books, on the one hand, and book chapters and books, on the other, do show a medium sized significant difference in both periods. In short, journal articles and book chapters show a similar behaviour. The decreases observable in journal articles, books and book chapters in the 2000-2009 period compared with the 1990-1999 period are significant in the case of books and book chapters only, although the size effects are rather small. In the case of journal articles, the changes are not significant.

\subsection{Number of years needed before TS publications are cited for the first time in relation to document type}

3.2.1. Median of years needed to receive a first citation and the mode of waiting time, in years, that accrues for first citations by publication type

Table 5 shows the median of years needed to receive a first citation and the mode of waiting time, in years, that accrues for first citations by document type for the whole period under analysis (1960-2015).

Table 5. Median and mode of years needed to receive a first citation for the whole period under analysis (1960-2015)

\begin{tabular}{|l|c|c|c|}
\hline \multicolumn{1}{|c|}{ Publication type } & Median & $\begin{array}{c}\text { Median absolute } \\
\text { deviation }\end{array}$ & Mode \\
\hline Book & 6.3 & 2.8 & 1 \\
\hline Book chapter & 6.1 & 1.4 & 3 \\
\hline Journal article & 5.7 & 1.5 & 2 \\
\hline Journal special issue & 4.6 & 1.4 & 1 \\
\hline
\end{tabular}

If we take the whole period of study, books are, together with journal special issues, the publication type that gets a first citation most rapidly (mode $=1$ ). However, $50 \%$ of books do not receive their first citation until the first 6.3 years after publication (MAD $=2.8$ ), while $50 \%$ of journal special issues receive their first citation before 4.6 years after publication. Thus, the period over which books are likely to receive their first citation is the longest of all document types. Conversely, the shortest period is found in journal special issues. Journal articles and book chapters are situated between these two values, although journal articles (mode $=2$ ) usually receive the first citation before book chapters do (mode $=3$ ), and the period over which they are likely to receive their first citation is in both cases around six years after publication (journal articles: $\mathrm{Mdn}=5.7$; book chapters: $\mathrm{Mdn}=6.1$ ). After running a Kruskal-Wallis test $\left(H[4]=371.6, p<0.001 ; \eta^{2}=0.02\right)$, pairwise comparisons showed that differences between all publication types were statistically significant. ${ }^{6}$ The largest effects were found between journal articles and books, on the one hand, and between books and book chapters, on the other.

The median and mode of years needed to receive the first citation by publication type and period is presented in Table 6.

\footnotetext{
${ }^{6}$ Journal articles and book chapters: $U=42426813.5, p<0.001, r=0.09$; journal articles and books: $U=19352948.5, p<0.001, r=0.14$; journal articles and journal special issues: $U=$ 725148.5, $p<0.001, r=0.43$; book chapters and books: $U=1965.1, p<0.001, r=0.12$; book chapters and journal special issues: $U=580247.5, p<0.001, r=0.49$; books and journal special issues: $U=368007, p<0.001, r=0.34$.
} 
Table 6. Median and mode of years needed to receive the first citation in relation to publication type and period ${ }^{7}$

\begin{tabular}{|c|c|c|c|c|c|c|}
\hline Publication type & $1960-1969$ & $1970-1979$ & 1980-1989 & 1990-1999 & $2000-2009$ & $2010-2015$ \\
\hline Journ & $\begin{array}{l}\mathrm{Moc} \\
\mathrm{n}=\end{array}$ & $\begin{array}{l}\text { Moc } \\
(n=\end{array}$ & $\begin{array}{l}\text { Mod } \\
(n=\end{array}$ & $\begin{array}{l}\text { Mo } \\
(n=\end{array}$ & $\begin{array}{c}M \\
(n\end{array}$ & $\begin{array}{l}\text { Mo } \\
(n=\end{array}$ \\
\hline Book & $\begin{array}{r}\text { Mdn }=17.5 \\
\text { Mode }=3 \\
(n=140)\end{array}$ & $\begin{array}{r}\text { Mdn }=20.0 \\
\text { Mode }=2 \\
(n=275)\end{array}$ & $\begin{array}{r}\text { Mdn }=11.0 \\
\text { Mode }=10 \\
(n=572)\end{array}$ & $\begin{array}{c}\text { Mdn } \\
\text { Mo } \\
(n=\end{array}$ & $\begin{array}{l}\text { Mo } \\
(n=\end{array}$ & $\begin{array}{r}\text { Mdn }=1.0 \\
\text { Mode }=1 \\
(n=589)\end{array}$ \\
\hline Book & $\begin{array}{r}\text { Mdn }=15.0 \\
\text { Mode }=3 \\
(n=129)\end{array}$ & $\begin{array}{r}\text { Mdn }=18.0 \\
\text { Mode }=2^{*} \\
(n=297)\end{array}$ & $\begin{array}{c}\text { Mdn }=13.0 \\
\text { Mode }=11 \\
(n=1002)\end{array}$ & $\begin{array}{r}\text { Mdn }=7.0 \\
\text { Mode }=5 \\
(n=2863)\end{array}$ & $\begin{array}{r}\text { Mdn }=4.0 \\
\text { Mode }=3 \\
(n=3906)\end{array}$ & $\begin{array}{r}\text { Mdn }=2.0 \\
\text { Mode }=2 \\
(n=948)\end{array}$ \\
\hline Journal special issue & $\begin{array}{r}\text { Mdn }=34.5 \\
\text { Mode }=30^{*} \\
(n=2)\end{array}$ & $\begin{array}{r}\text { Mdn }=21.0 \\
\text { Mode }=21^{*} \\
(n=8)\end{array}$ & $\begin{array}{r}\text { Mdn }=10.5 \\
\text { Mode }=7 \\
(n=24)\end{array}$ & $\begin{array}{r}\text { Mdn }=4.0 \\
\text { Mode }=3 \\
(n=58)\end{array}$ & $\begin{array}{r}\text { Mdn }=3.0 \\
\text { Mode }=1 \\
(n=100)\end{array}$ & $\begin{array}{r}\text { Mdn }=2.0 \\
\text { Mode }=1 \\
\quad(n=60)\end{array}$ \\
\hline
\end{tabular}

All publication types present a descending pattern as the decades go by from the 1970-1979 period onwards. In the 1980-1989 period, journal special issues are the fastest publication type in receiving their first citation (mode $=$ 7). Conversely, in the 1990-1999 period books take the lead (mode $=2$ ), whereas in the last two periods analysed (2000-2009 and 2010-2015), both journal special issues and books are the fastest publication types in receiving their first citation $(\operatorname{mode}=1)$, while journal articles and book chapters behave similarly (mode $=3$ and mode $=2$ in the 2000-2009 and 2010-2015 periods, respectively). We can conclude that in the last period analysed all publication types receive their first citation much faster than in previous periods and that the time needed to receive a first citation ranges from one to two years. At present, books and journal special issues are the fastest publication types when it comes to receiving their first citation, which is coincident with the results for the whole period (1960-2015) as shown in Table 5. They are followed by journal articles and book chapters, which attain their first citation two years after their publication.

Again, in order to find out whether the differences shown in Table 6 were statistically significant, we compared different document types and periods as we did in Table 4 (results are shown in Table 7).

Table 7. Omnibus tests and post-hoc tests by period and comparison tests by publication type

\begin{tabular}{|c|c|c|c|c|c|c|c|}
\hline \multicolumn{4}{|c|}{$\begin{array}{l}\text { Omnibus tests and post-hoc tests by publication } \\
\text { type }\end{array}$} & \multicolumn{4}{|c|}{ Comparison tests by publication type } \\
\hline \multicolumn{4}{|c|}{ 2000-2009: $H(2)=430.2, p<0.001, \eta^{2}=0.04$} & \multicolumn{4}{|c|}{$1990-1999$ vs. $2000-2009$} \\
\hline & $U$ & $p$ & $r$ & & $U$ & $\begin{array}{l}p \text { (one- } \\
\text { tailed) }\end{array}$ & $r$ \\
\hline $\begin{array}{l}\text { Journal articles vs. } \\
\text { book chapters }\end{array}$ & $1,355.4$ & $<0.001$ & 0.08 & $\begin{array}{l}\text { Journal } \\
\text { articles }\end{array}$ & 29033022 & $<0.001$ & 0.42 \\
\hline $\begin{array}{l}\text { Journal articles vs. } \\
\text { books }\end{array}$ & $1,942.5$ & $<0.001$ & 0.32 & Books & 33728059 & $<0.001$ & 0.39 \\
\hline $\begin{array}{l}\text { Book chapters vs. } \\
\text { books }\end{array}$ & -392.07 & $<0.001$ & 0.29 & $\begin{array}{l}\text { Book } \\
\text { chapters }\end{array}$ & 26366308 & $<0.001$ & 0.53 \\
\hline \multicolumn{4}{|c|}{ 2010-2015: $H(2)=217.9, p<0.001, \eta^{2}=0.04$} & & & & \\
\hline & $U$ & $p$ & $r$ & & & & \\
\hline $\begin{array}{l}\text { Journal articles vs. } \\
\text { book chapters }\end{array}$ & 517.4 & $<0.001$ & 0.23 & & & & \\
\hline $\begin{array}{l}\text { Journal articles vs. } \\
\text { books }\end{array}$ & 991.9 & $<0.001$ & 0.28 & & & & \\
\hline $\begin{array}{l}\text { Book chapters vs. } \\
\text { books }\end{array}$ & -474.6 & $<0.001$ & 0.24 & & & & \\
\hline
\end{tabular}

\footnotetext{
${ }^{7}$ Modes marked with an asterisk indicate that multiple modes exist. The lowest one is shown.
} 
The differences between journal articles and book chapters for the 20002009 period are small but statistically significant, whereas the differences between books and journal articles, on the one hand, and books and book chapters, on the other, are large. In the case of the 2010-2015 period, the differences are statistically significant, but small between book chapters and journal articles, on the one hand, and between book chapters and books, on the other. Conversely, the differences between journal articles and books are considerable. The decrease observed in the 2000-2009 period compared to the 1990-1999 period is statistically significant in the case of journal articles, books and book chapters, and effect sizes are large in all cases.

\subsubsection{Cumulative survival distribution of first citations by publication type}

Figure 2 presents the cumulative survival distribution by publication type created from life tables for each publication type.

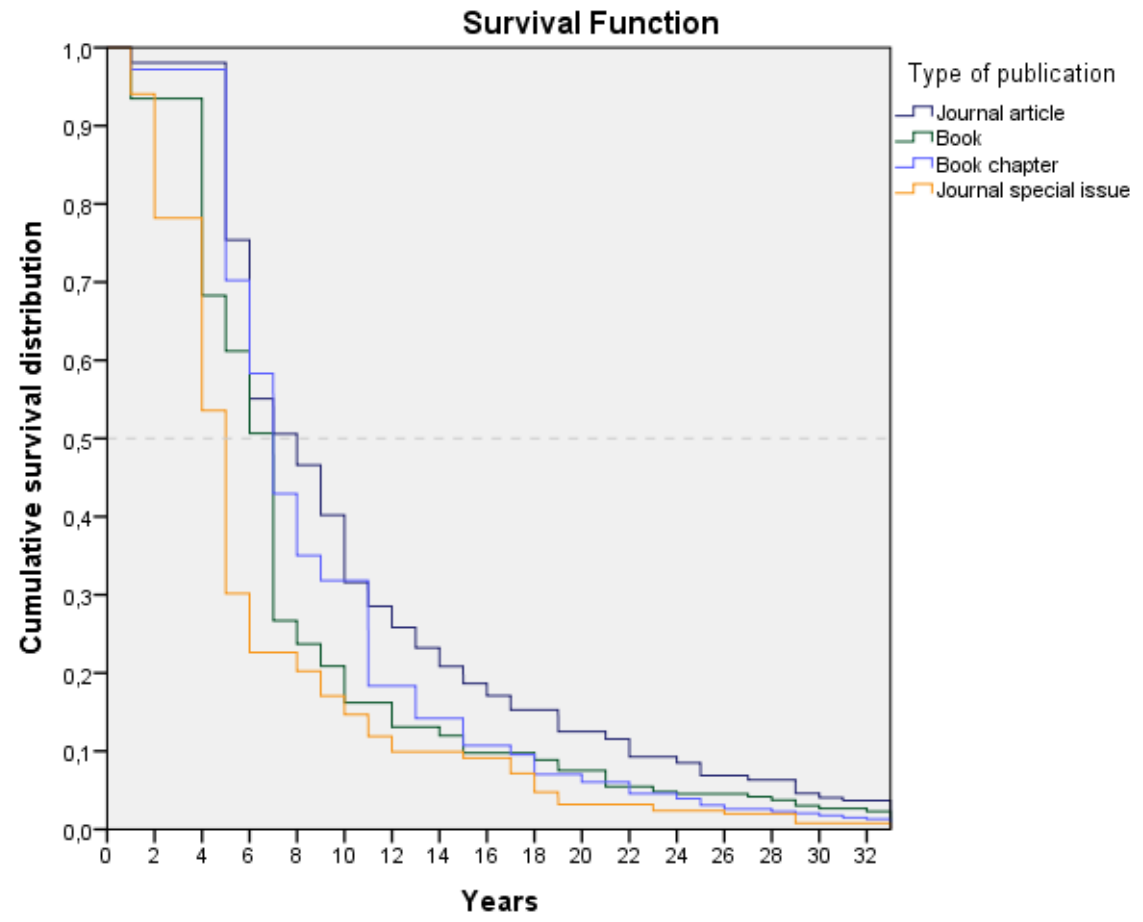

Figure 2. Cumulative survival distribution of first citations by publication type

This plot shows the likelihood that a specific type of publication will be cited for the first time as more years pass from the moment in which it was published. The slope of the likelihood of being cited for the first time for journal special issues is steeper than the rest. This means that the probability is high in the first years after publication, but it then drops quickly as years go by. The 50\% likelihood of being cited for the first time for journal special issues is situated between the fourth and sixth-year interval, and between the sixth and eight-year interval for journal articles, books and book chapters. This means that, after these intervals, the probability of these documents receiving a citation is lower than $50 \%$. The largest differences among publication types are situated between the likelihood of 0.2 to 0.6 and from years 5 to 11. At these cut-off points, some differences can be observed between journal special issues and books, on the one hand, and book chapters and journal articles, on the other, since the curves for book chapters and journal articles are less steep. It is noteworthy that journal articles are the publication type with the least steep slope, implying they are the publication type with the highest probability of being cited for the first time many years after publication, ranging from a likelihood of 0.3 to 0.1 from the $11^{\text {th }}$ to the 
$24^{\text {th }}$ year. Although differences exist between publication types, the curves for journal articles and book chapters do not differ significantly in accordance with the Gehan-Wilcoxon test $([1]=1.030, p>0.05)$.

\subsection{Aging patterns of TS publications in line with document type}

In this section, we present the results regarding the percentage of citations accrued on average by a TS publication in 2-year, 5-year, 10-year and 15-year time windows after publication. We have done this in order to describe the time distribution of citations, which can help us outline aging or obsolescence patterns of TS scientific literature in line with document type. The mean percentage of citations accrued by TS publications, by publication type and different citation windows is shown in Figure 3.

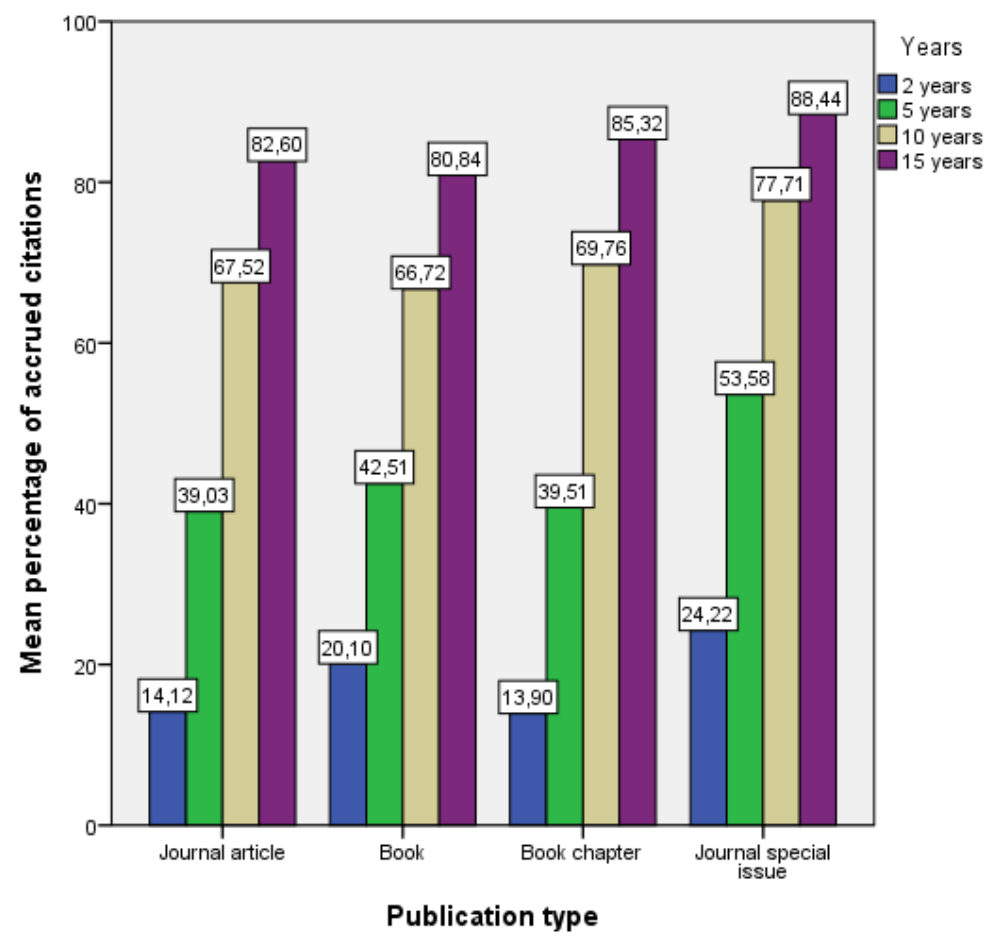

Figure 3. Mean percentages of citations accrued by publication type and citation windows

As can be observed, a 2-year citation window is not long enough to detect at least $25 \%$ of all citations for any publication type. With a 5-year citation window, the citations detected more than double those in a 2-year citation window, although only journal special issues achieve $50 \%$ of all their citations $(53.58 \%)$. In the case of journal articles, book chapters and books, only $39.03 \%, 39.51 \%$ and $42.51 \%$, respectively, of all citations are covered in a $5-$ year citation window. The percentage increases to $66.72 \%, 67.52 \%$ and $69.76 \%$ for books, journal articles and book chapters, respectively, using a 10 year citation window. When considering a 15-year citation window, all publication types are situated above $80 \%$, ranging from $80.84 \%$ (books) to $88.44 \%$ (journal special issues). It should be noted that the transition from a 10 -year citation window to a 15 -year one presents the smallest increase as compared to the previous citation windows. We ran Kruskal-Wallis tests for each citation window and post-hoc tests between all publication types (see Table 8). 
Table 8 . Omnibus tests and post-hoc tests by publication type for each citation window

\begin{tabular}{|c|c|c|c|}
\hline \multicolumn{4}{|c|}{ 2-year citation window: $H(3)=420.6, p<0.001, \eta^{2}=0.02$} \\
\hline & $U$ & $p$ & $r$ \\
\hline Journal articles vs. book chapters & 46235123 & $=0.981$ & 0.001 \\
\hline Journal articles vs. books & 19190316 & $<0.001$ & 0.15 \\
\hline Journal articles vs. journal special issues & 1073390.5 & $<0.001$ & 0.16 \\
\hline Book chapters vs. books & 17348975.5 & $<0.001$ & 0.15 \\
\hline Book chapters vs. journal special issues & 970057.5 & $<0.001$ & 0.16 \\
\hline Books vs. journal special issues & 545819.5 & $=0.465$ & 0.02 \\
\hline \multicolumn{4}{|c|}{ 5-year citation window: $H(3)=69.6, p<0.001, \eta^{2}=0.003$} \\
\hline & $U$ & $p$ & $r$ \\
\hline Journal articles vs. book chapters & 45778660.5 & $=0.192$ & 0.02 \\
\hline Journal articles vs. books & 20977145.5 & $<0.001$ & 0.06 \\
\hline Journal articles vs. journal special i & 1052834 & $<0.001$ & 0.17 \\
\hline Book chapters vs. books & 19170851 & $<0.001$ & 0.06 \\
\hline Book chapters vs. journal special issues & 960417 & $<0.001$ & 0.17 \\
\hline Books vs. journal special issues & 489088 & $<0.001$ & 0.12 \\
\hline \multicolumn{4}{|c|}{ 10-year citation window: $H(3)=41.8, p<0.001, \eta^{2}=0.002$} \\
\hline & $U$ & $p$ & $r$ \\
\hline Journal articles vs. book chapters & 45157265 & $<0.01$ & 0.03 \\
\hline Journal articles vs. books & 21859385 & $<0.001$ & 0.02 \\
\hline Journal articles vs. journal special issues & 1133118.5 & $<0.01$ & 0.11 \\
\hline Book chapters vs. books & 19245236 & $<0.001$ & 0.05 \\
\hline Book chapters vs. journal special issues & 1049721 & $<0.01$ & 0.08 \\
\hline Books vs. journal special issues & 476570 & $<0.001$ & 0.15 \\
\hline \multicolumn{4}{|c|}{ 15-year citation window: $H(3)=97.1, p<0.001, \eta^{2}=0.004$} \\
\hline & $U$ & $p$ & $r$ \\
\hline Journal articles vs. book chapters & 44913266 & $<0.001$ & 0.03 \\
\hline Journal articles vs. books & 21441630.5 & $<0.001$ & 0.04 \\
\hline Journal articles vs. journal special issues & 1185987.5 & $<0.05$ & 0.07 \\
\hline Book chapters vs. books & 18769158 & $<0.001$ & 0.07 \\
\hline Book chapters vs. journal special issues & 1104720.5 & $=0.113$ & 0.04 \\
\hline Books vs. journal special issues & 493357 & $<0.001$ & 0.12 \\
\hline
\end{tabular}

The largest differences between publication types are to be found in the 2-year time window. Except for books and journal special issues, which differ to some extent in the 5,10 and 15-year citation windows, the differences between publication types are smaller in size as the citation window increases.

\subsection{Cited half-life for TS publications depending on document type}

\subsubsection{Cited half-life by document type}

De Bellis (2009, p. 114) defines the concept of half-life as "the time during which half the total use of a given literature has been made". And he adds: "[a]t its simplest, if usage is estimated by citations, it is computed for a set of source documents published in a given year by subtracting that year from the median publication year of the papers citing the documents". As one of the objectives of this paper was to define a discipline-weighted citation window or cited half-life in order to establish the optimal citation window to be used in TS, we calculated the cited half-life (median) by publication type for the whole period of analysis (1960-2015) (see results in Table 9). We also calculated the citation peak (mode), that is, the waiting time, in years, in which most of the cited documents receive the most citations. The results related to the citation peaks are also presented in Table 9. 
Table 9. Cited half-life (median) and citation peak (mode) for the whole period under analysis (1960-2015)

\begin{tabular}{|l|c|c|c|}
\hline Publication type & Cited half-life & Median absolute deviation & Citation peak \\
\hline Book & 9.1 & 4.1 & 3 \\
\hline Book chapter & 7.7 & 2.9 & 5 \\
\hline Journal article & 7.4 & 2.7 & 3 \\
\hline Journal special issue & 5.7 & 3.0 & 3 \\
\hline
\end{tabular}

Books are the publication type with the longest cited half-life $(\mathrm{Mdn}=$ 9.1), while the shortest cited half-life is registered in journal special issues $(\mathrm{Mdn}=5.7)$. As seen in Table 5 and in Figure 2, this publication type is also the fastest in receiving a first citation. A Kruskal-Wallis test showed that there were differences between publication types $\left(H[4]=1550,2, p<0.001 ; \eta^{2}=\right.$ 0.02). Mann-Whitney post-hoc tests identified statistically significant differences between all publication types, although the largest ones were to be found between journal articles, book chapters and books, on the one hand, and journal special issues, on the other. Book chapters and journal articles have a similar cited half-life, ranging from 7.4 (journal articles) to 7.7 (book chapters). Even if the difference is statistically significant, the size effect is small. Dispersion in books is rather large (MAD $=4.1)$, indicating that many factors might influence their cited half-life, while journal articles present the smallest dispersion (MAD $=2.7)$.

Table 10 shows the cited half-life of all citations by publication type and decade. The last six years of the time span analysed in this paper (2010-2015) were not included since the time span is shorter than the cited half-lives identified in Table 9 and the results could therefore be biased.

Table 10. Cited half-life (median) by publication type and period

\begin{tabular}{|l|c|c|c|c|c|}
\hline & $\mathbf{1 9 6 0 - 1 9 6 9}$ & $\mathbf{1 9 7 0 - 1 9 7 9}$ & $\mathbf{1 9 8 0 - 1 9 8 9}$ & $\mathbf{1 9 9 0 - 1 9 9 9}$ & $\mathbf{2 0 0 0 - 2 0 0 9}$ \\
\hline Journal article & 29.4 & 26.8 & 16.6 & 8.9 & 5.5 \\
\hline Book & 32.0 & 27.6 & 18.5 & 9.1 & 5.8 \\
\hline Book chapter & 32.0 & 25.4 & 16.8 & 7.7 & 5.8 \\
\hline $\begin{array}{l}\text { Journal special } \\
\text { issue }\end{array}$ & 31.2 & 23.5 & 16.0 & 9.4 & 4.7 \\
\hline
\end{tabular}

There is no marked difference between publication types in the 19601969 period: the cited half-life ranges from 29.4 to 32.0 years. Cited half-lives for each publication type clearly descend as the decades go by, although there is a big leap between the 1970-1979 period (cited half-lives ranging from 23.5 to 27.6 years) and the $1980-1989$ period (16.0-18.5 years). There is also a big leap between 1980-1989 and 1990-1999 (7.7-9.4 years). In the case of the documents published from 2000 to 2009 , there are no relevant differences between publication types except for journal special issues, which have the shortest cited half-life (4.7 years). All other publication types range from 5.5 to 5.8 years.

As shown in Table 9, the citation peak for each publication type covering the whole period under analysis (1960-2015) is situated some years before their cited half-life. The citation peak in journal articles, books and journal special issues is in the third year, whereas for book chapters it is in the fifth year. Table 11 shows the citation peak by publication type and period. 
Table 11. Citation peak (mode) by publication type and period ${ }^{8}$

\begin{tabular}{|l|r|r|r|r|r|}
\hline & $1960-1969$ & $1970-1979$ & $1980-1989$ & $1990-1999$ & $2000-2009$ \\
\hline Journal article & $\begin{array}{r}4 \\
(n=583)\end{array}$ & $\begin{array}{r}30 \\
(n=1326)\end{array}$ & $\begin{array}{r}16 \\
(n=3390)\end{array}$ & $\begin{array}{r}9 \\
(n=8552)\end{array}$ & $\begin{array}{r}7 \\
(n=10,435)\end{array}$ \\
\hline Book & $\begin{array}{r}42 \\
(n=1927)\end{array}$ & $\begin{array}{r}31 \\
(n=2491)\end{array}$ & $\begin{array}{r}23 \\
(n=5536)\end{array}$ & $\begin{array}{r}11 \\
(n=14,903)\end{array}$ & $\begin{array}{r}3 \\
(n=9671)\end{array}$ \\
\hline Book chapter & 3 & 32 & 19 & 6 \\
$(n=424)$ & $(n=1439)$ & $(n=3434)$ & $(n=8704)$ & $(n=9115)$ \\
\hline Journal special issue & $30^{*}$ & $21^{*}$ & 16 & 3 \\
$(n=4)$ & $(n=10)$ & $(n=73)$ & $(n=353)$ & $(n=310)$ \\
\hline
\end{tabular}

The highly divergent figures indicate that many publication types from the sixties, seventies and eighties are frequently cited many years after their publication. In contrast, the citation peak descends gradually from the 19701979 to the 2000-2009 period for all document types. From 2000-2009, the citation peak is reached in the third year in the case of books and journal special issues, and in the sixth and seventh in the case of book chapters and journal articles, respectively. It is worth mentioning that in some periods the cited half-life is situated before the citation peak (Table 10). This would indicate that in those cases most citations are accrued during the publications' second half of their cited life, as also shown in Figure 4.

\subsubsection{Cumulative survival distribution of all citations by publication type}

Again, life tables were built to describe the waiting time, in years, of all citations by publication type. Figure 4 shows the cumulative survival distribution by publication type.

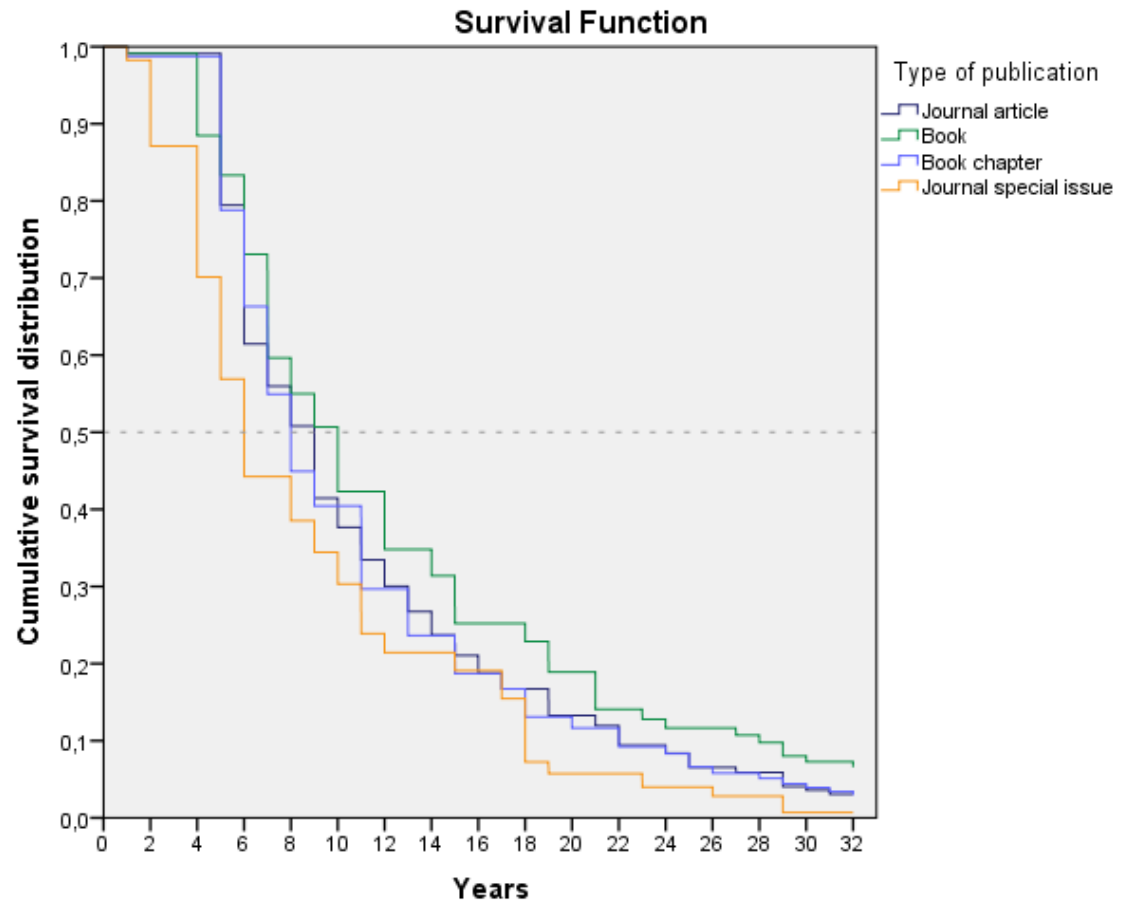

Figure 4. Cumulative survival distribution of all citations by publication type

The probability curves of being cited for journal articles and book chapters are very similar. Pairwise comparisons with the Gehan-Wilcoxon test showed that there are no statistical differences between them $([1]=1.340, p>$ $0.05)$. Journal special issues are the publication type with the steepest slope, while books show the most gradual one, which means that their likelihood of being cited is higher as the years go by after publication. The difference

\footnotetext{
${ }^{8}$ Modes marked with an asterisk indicate that multiple modes exist. The lowest one is shown.
} 
between these two publication types is more visible at a likelihood of 0.5 onwards. Generally speaking, the likelihood curves present three different cutoff points. From years 0 to $8-10$, the slope is very steep and the likelihood of being cited drops from 1 to 0.5 . The second period is situated from years 10 to 16-18. In this period, the likelihood of being cited drops from 0.5 to $0.17-0.25$. Finally, from years 18 to 32 the likelihood drops from 0.17-0.25.

\section{Discussion}

\subsection{Is TS a book-based discipline?}

Journals are the predominant outlet for research output for most natural science disciplines, while researchers in the social sciences and humanities have a wider range of research outlets aside from journal publishing, such as books or book chapters (Huang \& Chang, 2008, p. 1820). Different studies have shown that journal publishing has increased in the social sciences, but has decreased in the humanities (Hammarfelt, 2016, p. 118), which is the reason why Sivertsen $(2016$, p. 88$)$ affirms that "there is no evidence that book publishing is being replaced by journal publishing in the humanities", except for linguistics (van den Akker, 2016, p. 25).

According to BITRA's database, journal articles are also the most numerous research output in TS, accounting for $44.0 \%$ of the whole database (Franco Aixelá, 2001-2018). However, books and book chapters together account for $53.6 \%$ of the outputs from 1951 up to the present, whereas journal articles account for $46.3 \%$ in the same period. ${ }^{9}$ It is interesting to note that we obtain a different picture if we look at the last few years (2011-2018), the percentages there being $42.8 \%$ and $57.1 \%$, respectively. Taking a historical perspective, from the $1980 \mathrm{~s}$ on, books show a decreasing trend, descending from $23.3 \%$ to the present $7.8 \%$. Book chapters experience a steady increase from the 1950 's to 2010 (going from $11.7 \%$ to $44.3 \%$ ), and then drop again to $30.1 \%$ from then to 2018 . In contrast, journal articles show the reverse trend, descending from $70.9 \%$ in the 1950 's to $40.2 \%$ in 2010 , and then increasing up to $50.5 \%$ from then to 2018 .

This change of positions between book chapters and journal articles might reveal a change of trend in TS publishing practices due to different factors. One reason might be that, at present, there are relatively less specialised conferences (and, consequently, less proceedings in the form of books), as compared to specialised journals, which have increased exponentially over the last few decades. ${ }^{10}$ Moreover, it would probably be an error to neglect the effect that new evaluation systems converging with the traditional ones in the natural sciences might be having on TS scholars' publication habits. However, it might also be that journal articles - which unlike conference proceedings are systematically placed on the Internet - are nowadays easier to spot for the BITRA database compilers, which would represent a bias for our study.

Paradoxically, although humanities scholars publish more journal articles than books, bibliometric studies show that they tend to cite books more often than other document types (Huang \& Chang, 2008, p. 1823-4; see also Hammarfelt, 2016, p. 120; Rovira-Esteva, Franco Aixelá \& Olalla-Soler, 2020). There are notable differences within the humanities in the citing of

\footnotetext{
${ }^{9}$ Journal special issues and $\mathrm{PhD}$ theses were excluded from this calculation because the former is not an individual document type comparable to the rest, and the latter has a very specific academic function and is usually written only once in a scholars' career.

${ }^{10}$ According to RETI (Biblioteca d'Humanitats. Universitat Autònoma de Barcelona, 2018), up to the 1980s there were only 11 T\&I journals. In the 1980s, 1990s and 2000s 18, 32 and 46 new specialised journals, respectively, were born. While in the last 19 years T\&I scholars have 27 new titles to choose from. Altogether they make up a list of 134 active journals with at least $50 \%$ of journal articles devoted to TS issues.
} 
sources, and the percentage of references to authored and edited books varies from $88 \%$ in religion or $81 \%$ in literature to only $49 \%$ in linguistics (Hammarfelt, 2016, p. 118-9). Based on these percentages, Hammarfelt considers religion and literature to be book-based disciplines, while he acknowledges that journals play an important role in linguistics, since more than half of cited works are journal articles. After a literature review, Huang and Chang (2008, p. 1823) also found substantial differences among humanistic disciplines, since citations to books accounted for $88.2 \%$ in religion, $83 \%$ in literature, $76.9 \%$ in arts and $60.8 \%$ in linguistics.

Previous citation studies have also shown a heavy reliance on books as reference sources in TS (Rovira-Esteva \& Orero, 2011, p. 242; see also Franco Aixelá \& Rovira-Esteva, 2018; Gile, 2005; Nasr, 2010). For instance, RoviraEsteva and Orero's (2011, p. 242) analysis based on 500 journal articles published in TS journals indexed in WoS databases found that $50 \%$ of the citations in journal articles published from 2007 to 2009 were to books or book chapters. In their study of TS research in Spanish-speaking countries, Franco Aixelá and Rovira-Esteva (2018), discovered that $82.3 \%$ of the most cited works originally published in Spanish were books.

Our study also confirms the relevant role of books as reference sources. Despite the fact that journal articles are the most frequent document type in our database, books are the publication type that concentrates more citations per document. Differences are observable between books and the rest of the document types. However, journal articles, book chapters and journal special issues do not differ significantly among themselves. In the case of books, the mean for citations per document tends to decrease over time, while the median for citations is constant since it is situated in a range between one and two citations per document. One reason to explain this tendency could be the fact that, the more recent the publication, the less time it has had to accrue citations. A significant decrease in the number of citations accrued by books and book chapters in the 2000-2009 period, as compared to the 1990-1999 period, has been detected, but this was not the case with journal articles, which might also indicate a change of trend.

In summary, with the data available and comparing TS with other disciplines within the humanities, we can affirm that TS is a book-based discipline as far as citations are concerned, but not necessarily so if we look at research outputs, which are mainly in the shape of journal articles. According to the data available, we might be witnessing a transition period in which the discipline is evolving from a book-based discipline, like literature, to a journal-based field, like linguistics.

\subsection{Average number of years needed for a TS publication to receive its first citation in relation to document type}

As already noted in the introduction, from the total of 66,407 documents eligible for analysis only $25,303(38.1 \%)$ had at least one citation detected in our database. This means that $61.8 \%$ of documents had no citations detected. This piece of information is highly relevant from the point of view of research assessment through citation counts since what should be considered normal for a TS publication is not receiving any citation at all. Bunia (2016, p. 133) points out that sometimes such low numbers are not a product of deficiencies in data, but rather a reflection of low citation patterns. He also puts forward two reasons to explain why each scholar can expect only a little attention and very few (if any) citations by peers. On the one hand, scholars quote from other disciplines and, on the other, "quotations cluster around a certain few 'big names', who are quoted abundantly" (Bunia, 2016, p. 145), the abovementioned "Matthew effect". Hammarfelt (2016, p. 126) considers the varied audience, rural organization of the field and low dependence on colleagues to 
be characteristics of the humanities that influence referencing practice and citation patterns.

TS is considered to be an inter-disciplinary field and, as such, scholars can be expected to quote authors from neighboring disciplines. This could be affecting the results of our analysis. Hammarfelt (2016, p. 125) argues that "[a] less demarcated discipline lacking a central core is heavily influenced by other research fields and therefore more interdisciplinary in referencing practices". It could be that TS scholars read and quote colleagues from other disciplines, but do not receive citations in return. In order to empirically determine whether TS is a low or high citation discipline we should not only quantify the number of sources in reference lists, but also carry out a qualitative analysis to categorize them as belonging to TS or not. This, in turn, would allow us to examine whether its interdisciplinary nature is limiting the potential for TS scholars to receive 'rewards' in the form of citations.

According to our data, books are, together with journal special issues, the publication type that gets a first citation more rapidly (mode $=1$ ). However, $50 \%$ of books do not receive their first citation before the first 6.3 years after publication ( $\mathrm{MAD}=2.8$ ), while $50 \%$ of journal special issues receive their first citation before the first 4.6 years after publication. Journal articles usually receive their first citation (mode $=2$ ) before book chapters (mode $=3$ ), but the period over which both document types are likely to receive their first citation is around six years after publication. The differences between all publication types were statistically significant. The largest effects were found between journal articles and books, on the one hand, and between book chapters and books, on the other. At present, books and journal special issues are the fastest publication types in receiving their first citation, which is coincident with the results for the whole period (1960-2015). They are followed by journal articles and book chapters, which accrue their first citation two years after publication.

The differences between journal articles and book chapters for the 20002009 period are small but statistically significant, whereas the differences between books and journal articles, on the one hand, and books and book chapters, on the other, are large. The decrease observed in the 2000-2009 period with regard to the 1990-1999 one is statistically significant in the case of journal articles, books and book chapters, and effect sizes are big in all cases.

A $50 \%$ likelihood of being cited for the first time in the case of journal special issues is situated between four and six years, and between six and eight years for journal articles, books and book chapters. The likelihood of being cited for the first time in the case of book chapters and especially in the case of journal articles decreases gradually as time advances, while the decrease is steeper in the case of books and journal special issues. It is noteworthy that journal articles are the publication type in which the likelihood of being cited for the first time decreases at a slower pace as time advances after publication.

In the earlier periods covered by our analysis the median of years needed to receive a first citation is very high, which might be due to the fact that those authors were not cited by their contemporaries, but rather by later scholars, when TS started to formally develop as a discipline and a revision of the socalled classics or reference texts took place.

\subsection{Percentage of citations that can be accrued by a TS publication in a 2- year, 5-year, 10-year and 15-year time window in relation to document type}

De Bellis $(2009$, p. 113) affirms that scientific literature "grows old and loses, partially or totally, its initial power of attractiveness". He further adds that "scientific literature ages more quickly than literature in the social sciences and the humanities". That is to say, "[c]ontrary to many other fields of science, much of what we humanists produce can have an effect in the long(er) run" (van den Akker, 2016, p. 25). TS is no exception to this 
durability of the "classics". At the time this article was written, there were 75 documents to which more than 100 citations had been detected in BITRA. No less than 69 of them $(92 \%)$ had been published in the last century and were still being profusely cited nowadays in spite of being 20 or more years old (see Franco Aixelá 2013 for a list of the most cited and the probable reasons of their durability).

The process by which the use of a research output declines with age is called "obsolescence". De Bellis (2009, p. 114) argues that an exact determination of the rate of obsolescence in different fields is a desirable task not only in order to better differentiate the various types of scholarly activity, "but also for placing in a more meaningful context any indicator of scientific value based on quantitative criteria". Obsolescence in scientific literature can be evaluated through the time distribution of citations. More specifically, "if a document is cited soon after its publication and then quickly forgotten its obsolescence is high, whereas if it continues to be cited in the years to come, as is usual in social sciences and the humanities, its obsolescence is low" (De Bellis, 2009, p. 114).

According to our analysis, in the first two years after publication, individual document types have accrued a rather small percentage of citations (book chapters $13.9 \%$, journal articles $14.12 \%$, and books $20.10 \%$ ), whereas journal special issues approach $25 \%$. Five years after publication, only journal special issues surpass the 50\% figure, while journal articles and book chapters hardly reach $40 \%$ and books achieve $42.51 \%$. Ten years after publication, journal special issues are the document type to accrue more citations (77.71\%), followed by book chapters $(69.76 \%)$, journal articles $(67.72 \%)$, and books $(66.72 \%)$. In a 15 -year time window, journal special issues take the lead again with $88.44 \%$ of total citations accrued, followed by book chapters $(85.32 \%)$, journal articles $(81.60 \%)$ and books $(80.84 \%)$.

If we compare our results with those obtained by Huang and Chang (2008, p. 1825-6) after conducting a thorough literature review on the age distribution of citations in social science and humanities research, we can affirm that TS shows a medium obsolescence rate. In other words, it behaves as a social science discipline rather than a traditional humanistic one, since it tends to cite more recent documents than literature, for example. Nevertheless, this is too abstract a concept for research evaluation, since we need to choose a time window, i.e., within how many years after publication should citations be counted in order to measure the impact of a piece of research. We have shown that TS follows the delayed rise/slow decline pattern. Therefore, a short time window of one or two years is not adequate because it takes much longer to be recognised and cited. Using such a time window would then result in unfair evaluations. The results in Section 3.2. show that the likelihood of being cited for the first time many years after publication is high, especially in the case of journal articles. This is a symptom of low obsolescence, since it means that in some cases it takes a long time for research to reveal its full impact. Therefore, when measuring the impact of research in TS, the lifetime, as well as the distribution of citations to the publication over time, must be considered. It is our contention that sustainability and durability should also be measured in TS research assessment exercises and be counted as a merit to compensate for short citation windows.

Price (1970, as cited in Huang \& Chang, 2008, p. 1825) suggested that the age distribution of the references could be used as a measure to judge the "hardness" of that field according to the following division: when around $42 \%$ of the references are published within five years in a subject discipline, the subject can be considered to belong to the realm of hard science; when 21$42 \%$ of the references are published within five years, it is soft science; and when references published within the last five years account for less than $21 \%$, the discipline is a nonscience. If we apply this 5 -year principle to TS we 
find that the discipline meets the criteria of a soft science for journal articles and book chapters, and those of a hard science in the case of books and journal special issues. However, it is obvious that TS does not generally demand recent and timely information as the hard sciences usually do. A 2-year window is clearly inadequate in TS, since most documents have not even received their first citation yet and those that have been cited in such a short period have accrued only between $12 \%-20 \%$ of citations. A 5 -year period would also be insufficient if we want to accrue at least half of the quotations. As Huang and Chang (2008, p. 1825) complain, "[e]valuations of SS\&H [Social Sciences and Humanities] research should not adopt the citation counts in a short period as a measure to assess SS\&H research output", since, as is the case with TS, the impact of its literature is usually long-term rather than short-term. In TS, longer 'mid-term' citation windows may be needed, ranging from 1-4 years to 1-6 years instead of 1-3 years. Nevertheless, a 5-year citation window should be a minimum requirement if we wish to obtain a meaningful analysis and a reasonably fair assessment.

\subsection{Cited half-life for TS publications contingent on document type}

Social sciences and humanities researchers cite older literatures, using literature published within the last 10 years or even earlier, which implies that their literatures have longer half-lives (Huang \& Chang, 2008, p. 1826-7).

According to our study, books are the publication type with the longest cited half-life (Mdn $=9.1)$, while the shortest cited half-life is registered in journal special issues $(\mathrm{Mdn}=5.7)$. Book chapters and journal articles have a similar cited half-life ( $\mathrm{Mdn}=7.7$ and 7.4 years, respectively). In the case of the documents published from 2000 to 2009 , ranging from 5.5 to 5.8 years, there are no relevant differences between publication types except for journal special issues, which have the shortest cited half-life (4.7 years). The likelihood of being cited as time advances is very similar both for journal articles and book chapters, while in the case of books this likelihood descends more gradually over time, which means that their half-life is longer. The documents published in the last period under analysis (2000-2009) reach their peak of citations in the third (books and journal special issues), sixth (book chapters) and seventh year (journal articles) after publication. Therefore, in TS and contrary to other fields of science, the citation peaks of the last two document types tend to occur late when compared with books. Nederhof (1986, as cited in Bunia, 2016, p. 144) claims that in some humanist disciplines, the impact of journal articles reaches a peak in the third year but, according to our data, this citation window appears to be inadequate for TS.

In summary, taking into account the whole period under analysis three different patterns can be identified. Books, as journal articles and journal special issues, reach their peak three years after publication, but their cited half-life is the longest (9.1). Book chapters (7.7) and journal articles (7.4) have similar half-lives, but book chapters show a lower obsolescence pattern, reaching their peak in the fifth year; whereas journal articles reach their peak in the third year. Journal special issues are the document type with the highest obsolescence pattern, since their cited half-life is the shortest (5.7 years).

Hammarfelt $(2016$, p. 125) believes that citation patterns are also determined by the number of researchers engaged in a specific topic. $\mathrm{He}$ further adds that "[i]n an urban field, it is important to keep up with the 'research front' and cite recent literature, while the age of sources plays less of a role in rural fields". For him, the distinction between rural and urban involves the 'density' of a discipline or a research area. If many researchers are working on the same problem, then the research area is described as urban, while a less populated discipline is deemed rural and the speed of publication is considerably slower. As for TS, the fact that the number of years needed to receive a first citation is decreasing might indicate that TS is becoming a more 
urban discipline. Moreover, the number of scholars researching in TS has increased enormously since the establishment of TS as a discipline in the 1970s. ${ }^{11}$ However, they are quite scattered among different noninterconnected subfields and presumably do not tend to cite each other. In fact, low citation frequencies might be a symptom that we lack strong group cohesion. Therefore, it becomes necessary to compensate for the smaller volumes of citations in TS, as in other humanities disciplines, by using longer citation windows.

\section{Concluding remarks}

Meaningful and fair assessments based on citation impact indicators need to acknowledge the vast difference between research fields gathered under the umbrella of the humanities. To our knowledge, little research concerning publication and citing practices has been done in TS to account for its idiosyncrasy.

In order to determine a TS field-weighted citation impact to set a benchmark for scholars' output assessment, we carried out an intradisciplinary large-scale study covering a time span of 55 years (1960-2015) based on an ad-hoc database including nearly 28,000 items. The calculation of a normalised citation impact of TS academic literature according to different document types is, thus, the main contribution of this paper.

Thanks to our bibliometric approach in analysing citation and aging patterns within TS, we have been able to answer all of the research questions posed at the beginning of this paper. We have shown that, although journal articles are the most frequent research output in TS, books and book chapters together are the document types cited the most. However, our results indicate that TS currently lies in between a book-based field, such as literary studies, and a more journal-based one, such as linguistics. Nevertheless, books are a very important research output and even more so a vital reference resource, so that their role in TS research should not be neglected and should be given greater weight in any assessment.

As happens in most fields of knowledge, not receiving any citation is the norm (61.8\% of cases, according to BITRA). Therefore, when assessing how a scholar's output is performing in terms of the number of citations received, any figure observed should be compared to the expected rate for similar publications and periods.

Books and journal special issues tend to get a first citation one year after publication, whereas it takes two and three years for journal articles and book chapters, respectively. However, while $50 \%$ of journal special issues receive their first citation 4.6 years after publication, in the rest of document types it takes around six years for a similar result. This means that, generally speaking, a work's impact unfolds much later than the original publication i.e., the likelihood of being cited for the first time many years after publication is high, especially in the case of journal articles. According to our results, journal special issues are the publication type with the shortest half-life, books have the longest, while book chapters and journal articles lie somewhere in

\footnotetext{
${ }^{11}$ There is no official census of TS scholars, but we do have some empirical data that might give us an idea of the discipline's growth. For instance, according to BITRA (Franco Aixelá, 2001-2018), up to the 1980s only 109 Ph.D. theses were submitted within TS. In the next thirty years the increase is dramatic, with 193 (1980s), 570 (1990s) and 1143 (2000s) TS theses. In the last seven years (2011-2017) we have already detected no fewer than 1194 Ph.D. theses. Altogether they make up a list of 3209 Ph.D. theses, all of which dealing with TS (not including in any of these periods the numerous theses which are annotated translations, but do not address translation as such).
} 
between. In short, compared to other disciplines, TS shows a medium obsolescence rate.

The period it takes for TS research to reveal its full impact depends on the document type, but our results show that a 2-year window is very inadequate for TS, since different document types have only accrued at most between $12 \%-20 \%$ of citations. Therefore, to develop assessment criteria that are in tune with research and citing practices in TS, at least a 5-year timeframe should be used.

This study is innovative in the sense that it has depicted the characteristics of referencing patterns in TS. However, it presents several limitations that we need to be aware of. On the one hand, only $10 \%$ of the references included in the database used have been mined for TS citations. It also needs to be pointed out that our sample, albeit large, has some bias with respect to the entire BITRA database as regards citation mining and even more so when we take into account the huge number of publications. As far as the language of publication and the topics covered are concerned, deviations in citation mining are not particularly noteworthy. At the same time, as mentioned before, it is important to bear in mind that, for operative reasons derived from its own situatedness, BITRA's coverage of research performed in Western languages is much more complete than in African or Eastern languages. This said, to our knowledge, there is no alternative bibliographical repertoire with a better general coverage of Eastern and African TS than BITRA. Also, there is an over-representation of research by citers from 2006 onwards, of journal articles as a document type, and of open access. These biases are explained not only for operative reasons (accessibility of documents and cost-effectiveness of the mining), but also for academic reasons, with the rationale that scholars might be more interested in the citation trends of more recent research. It should also be noted that BITRA excludes self-citing, which might be a disadvantage for co-authored contributions.

On the other hand, the language used, the topic, the approach, the journal or publishing house's prestige, the kind of access, the author's reputation, or even the ratio between the number of available journals (and number of issues per year) along with the number of scholars publishing in the field, to name the most obvious issues, could all be confounding variables i.e., other factors besides document type that are affecting the work's impact. Therefore, their respective influence should also be researched in the future.

We hope to have contributed to a greater knowledge not only of citation patterns contingent on document type, but also of the social and intellectual organisation of TS research, as well as its evolution over time, a contribution to understanding TS in its own terms. In this sense, we hope we have achieved a solid departure point for disciplinary self-reflection in order to identify where we stand now and where we might be going.

\section{Acknowledgement}

This article has been partially funded by the Department of Translation, Interpreting and East Asian Studies of the Autonomous University of Barcelona.

\section{References}

Biblioteca d'Humanitats. Universitat Autònoma de Barcelona. (2018). RETI: Revistes dels estudis de Traducció $i$ Interpretació: Indicadors de qualitat. [Quality indicators for TS Journals]. Retrieved from http://www.uab.cat/libraries/reti

Bouabid, H. (2011). Revisiting citation aging: A model for citation distribution and life-cycle prediction. Scientometrics, 88(1), 199-211. http://doi.org/10.1007/ s11192-011-0370-5 
Bunia, R. (2016). Quotation statistics and culture in literature and in other humanist disciplines. In M. Ochsner, S. E. Hug, \& D. Hans-Dieter (Eds.), Research assessment in the Humanities: Towards criteria and procedures (pp. 133-150). Zürich: Springer Open. http://doi.org/0.1007/978-3-319-29016-4

De Bellis, N. (2009). Bibliometrics and citation analysis. From the science citation index to cybermetrics. Lanham, Maryland; Toronto; Plymouth, UK: The Scarecrow Press.

Franco Aixelá, J. (2001-2018). BITRA (Bibliography of Interpreting and Translation) Open-access bibliographical database. http://doi.org/10.14198/bitra

Franco Aixelá, J. (2010a). Un cálculo preliminar del impacto de las publicaciones de traducción e interpretación escritas originalmente en español [A preliminary estimation of the impact of publications dealing with translation and interpreting originally written in Spanish]. In M. López-Campos, R.; Balbuena, Carmen; Álvarez (Ed.), Traducción y modernidad. Textos científicos, jurídicos, económicos u audiovisuales (pp. 371-389). Córdoba: Universidad de Córdoba.

Franco Aixelá, J. (2010b). Una visión global de las publicaciones con mayor impacto en teoría de la traducción [An overview of the highest-impact publications on the theory of translation]. Letras, 48, 229-252.

Franco Aixelá, J. (2013). Who's who and what's what in Translation Studies: A preliminary approach. In C. M. Way, S. Vandepitte, R. Meylaerts, \& M. Bartłomiejczyk (Eds.), Tracks and treks in Translation Studies (pp. 7-28). Amsterdam: John Benjamins. http://doi.org/10.1075/btl.108.01aix

Franco Aixelá, J., Rovira-Esteva, S. (2015). Publishing and impact criteria, and their bearing on Translation Studies: In search of comparability. Perspectives: Studies in Translatology, 23(2), 265-283. http://doi.org/10.1080/0907676X.2014.972419

Franco Aixelá, J., \& Rovira-Esteva, S. (2018). A bibliometric overview of Translation-Studies research in Spanish-speaking countries. In Á. Vidal, \& R. A. Valdeón (Eds.), Routledge Handbook of Spanish Translation Studies. Routledge.

Gile, D. (2000). The history of research into conference interpreting: A Scientometric Approach. Target, 12(2), 297-321.

Gile, D. (2005). Citation patterns in the T\&I didactics literature. Forum, 3(2), 85-103. http://doi.org/10.1075/forum.3.2.05gil

Grbić, N. (2007). Where do we come from? What are we? Where are we going? A Bibliometrical analysis of writings and research on sign language interpreting. The Sign Language Translator \& Interpreter, 1(1), 15-51.

Grbić, N., \& Pöllabauer, S. (2008). To count or not to count: Scientometrics as a methodological tool for investigating research on Translation and Interpreting. Translation and Interpreting Studies, 3(1-2), 87-146.

Hammarfelt, B. (2016). Beyond coverage: Toward a bibliometrics for the Humanities. In M. Ochsner, S. E. Hug, \& D. Hans-Dieter (Eds.), Research assessment in the Humanities: Towards criteria and procedures (pp. 115-131). Zürich: Springer Open. https://doi.org/10.1007/978-3-319-29016-4_10

Hellqvist, B. (2010). Referencing in the Humanities and its implications for citation analysis. Journal of the American Society for Information Science and Technology, 61(2), 310-318.

Huang, M.-H., \& Chang, Y. (2008). Characteristics of research output in Social Sciences and Humanities: From a research evaluation perspective. Journal of the American Society for Information Science and Technology, 59(11), 1819-1828.

Metzger, M. (2006). Salient studies of signed language interpreting in the context of community interpreting scholarship. Linguistica Antverpiensia NS, 5, 263-291.

Moed, H. F. (2005). Citation analysis in research evaluation. Dordrecht: Springer.

Moed, H. F., Van Leeuwen, T. N., \& Reedijk, J. (1999). Towards appropriate indicators of journal impact. Scientometrics, 46(3), 575-589. http://doi.org/ 10.1007/BF02459613

Nasr, M. (2010). La didactique de la traduction - une étude scientométrique [The didactics of translation - a scientometric study] (Unpublished doctoral dissertation). Université Paris III - Sorbonne Nouvelle, France.

Pöchhacker, F. (1995). Writings and Research on Interpretation: A Bibliographic Analysis. The Interpreters' Newsletter, 6, 17-31.

Pöllabauer, S. (2006). 'During the interview, the interpreter will provide a faithful translation'. The potentials and pitfalls of researching interpreting in immigration, asylum, and police settings: Methodology and research paradigms. Linguistica Antverpiensia NS, 5, 229-244. 
Rovira-Esteva, S., Franco Aixelá, J., \& Olalla-Soler, C. (2020). A bibliometric study of co-authorship in Translation Studies. Onomázein. Revista de filología, lingüística y traducción, 47. http://doi.org/10.7764/onomazein.47.09

Rovira-Esteva, S., \& Orero, P. (2011). A contrastive analysis of the main benchmarking tools for research assessment in translation and interpreting: The Spanish approach. Perspectives Studies in Translatology, 19(3), 233-251.

Sivertsen, G. (2016). Publication-based funding: The Norwegian model. In M. Ochsner, S. E. Hug, \& D. Hans-Dieter (Eds.), Research assessment in the Humanities: Towards criteria and procedures (pp. 79-90). Zürich: Springer Open. http://doi.org/10.1007/978-3-319-29016-4

Sugimoto, C. R., \& Larivière, V. (2018). Measuring Research: What Everyone Needs to Know. Oxford: Oxford University Press.

van den Akker, W. (2016). Yes we should; Research assessment in the Humanities. In M. Ochsner, S. E. Hug, \& D. Hans-Dieter (Eds.), Research assessment in the Humanities: Towards criteria and procedures (pp. 23-30). Zürich: Springer Open. http://doi.org/0.1007/978-3-319-29016-4

Waltman, L., \& van Eck, N. J. (2013). Source normalized indicators of citation impact: An overview of different approaches and an empirical comparison. Scientometrics, 96(3), 699-716. http://doi.org/10.1007/s11192-012-0913-4

Wouters, P., Thelwall, M., Kousha, K., Waltman, L., de Rijcke, S., Rushforth, A., \& Franssen, T. (2015). The metric tide. Literature review (Supplementary report I to the Independent Review of the Role of Metrics in Research Assessment and Management). HEFCE. http://doi.org/10.13140/RG.2.1.5066.352 